\title{
PENGEMBANGAN BAHAN AJAR MATA KULIAH PRAKTIKUM IPS SD PENGARUHNYA TERHADAP PRESTASI BELAJAR
}

\author{
${ }^{1}$ Yulina Ismiyanti, ${ }^{2}$ Andarini Permata Cahyaningtyas \\ 1yulinaismiyanti@unissula.ac.id, 2andarinipermata@unissula.ac.id \\ Pendidikan Guru Sekolah Dasar, Fakultas Keguruan dan Ilmu Pendidikan, \\ Universitas Islam Sultan Agung
}

\begin{abstract}
ABSTRAK
Berdasarkan field study, pembelajaran Praktikum IPS SD di Prodi PGSD UNISSULA masih mengandalkan instruksi dosen semata. Mahasiswa terlihat masih kebingungan selama kegiatan praktikum karena ketiadaan bahan ajar yang harusnya menjelaskan langkah-langkah praktikum. Sehingga membuat mereka belum bisa mandiri dalam pembelajaran. Padahal, kegiatan praktikum IPS tidak hanya terbatas di laboratorium IPS. Praktikum IPS melibatkan laboratorium di lapangan atau lingkungan sebagai objek studi ilmu sosial. Oleh karena itu bahan ajar praktikum IPS sangat diperlukan untuk memfasilitasi mahasiswa selama praktikum baik indor atau outdor. Penelitian ini merupakan Researh and Development $(R \& D)$, dengan prosedur pendahuluan, pengembangan, serta validasi. Desain yang dipilih yaitu, Post Test Only Control Design. Sumber data penelitian ini ialah mahasiswa semester IVA yaitu kelas eksperimen, dan IVB kelas kontrol Prodi PGSD FKIP UNISSULA tahun pelajaran 2018/2019. Instrumen pengumpulan data pada penelitian ini yaitu wawancara, lembar validasi ahli, dan soal tes. Penelitian ini menghasilkan produk berupa buku panduan praktikum IPS SD yang berisi kompetensi pembelajaran, informasi pendukung, petunjuk belajar, lembar kerja. Prestasi belajar dari analisis uji $\mathrm{T}$, kelas eksperimen dengan rata-rata 84,74 lebih tinggi dari kelas kontrol 78,50.
\end{abstract}

Kata kunci: bahan ajar, Praktikum IPS SD, prestasi belajar.

\section{PENDAHULUAN}

Praktikum IPS SD adalah mata

kuliah wajib bagi mahasiswa program

studi Pendidikan Guru Sekolah Dasar

(PGSD) jenjang S1 berisi praktik nyata

teori-teori yang dipelajari dalam

pembelajaran IPS SD serta praktik

perencanaan, pelaksanaan, dan evaluasi pembelajaran IPS di SD. Mata kuliah Praktikum IPS merupakan bagian dari tujuan studi sosial. Bahwa studi sosial bertujuan mempelajari dan memecahakan permasalahan sosial untuk membekali mahasiswa agar menjadi warga negara yang baik berpengetahuan, memiliki kecakapan 
sosial serta bermanfaat bagi lingkungan (Hidayati, 2009: 24).

\section{Kenyataan dilapangan} pembelajaran Praktikum IPS SD di Prodi PGSD UNISSULA masih mengandalkan instruksi dari dosen. Oleh karena itu, mahasiswa terlihat masih kebingungan selama pelaksanaan praktikum karena ketiadaan bahan ajar yang memandu pelaksanaan kegiatan praktikum, yang membuat mereka belum bisa mandiri dalam pembelajaran Praktikum IPS. Padahal, kegiatan praktikum IPS tidah hanya terbatas di laboratorium IPS semata. Praktikum IPS melibatkan laboratorium di lapanngan atau lingkungan sebagai objek studi ilmu sosial. Oleh karena itu bahan ajar Praktikum IPS sangat diperlukan untuk memfasilitasi mahasiswa dalam kegiatan praktikum guna meningkatan prestasi belajar mahasiswa.

Dengan adanya bahan ajar praktikum IPS diharapkan mahasiswa bisa mempelajari sebelumnya kegiatan yang akan dilaksanakan serta mampu menemukan sendiri pengetahuannya melalui langkah-langkah dalam bahan ajar tersebut. Bahan ajar praktikum diharapkan memudahkan mahasiswa selama kegitan praktik sehingga mereka menjadi lebih mantap dalam melaksanakan praktikum. Penelitian ini mengakaji : (1) bagaimana karakteristik bahan ajar mata kuliah Praktikum IPS SD? (2) apakah bahan ajar mata kuliah praktikum IPS berpengaruh prestasi belajar?

Hasil penelitian ini diharapkan mampu memberikan manfaat secra teoritis yaitu menjadi referensi dalam mata kuliah Praktikum IPS SD dan untuk penelitian selanjutnya. Serta manfaat praktis yaitu memfasilitasi mahasiswa dalam kegiatan praktikum IPS baik di dalam maupun di luar laboratorium. Mensistematiskan pembelajaran mata kuliah praktikum IPS SD serta memudahkan dosen dalam mengistruksikan kegiatan praktik.

Praktikum IPS adalah realisasi dari teori pembelajaran agar teori tersebut menjadi lebih konkrit dan mudah dipahami oleh mahasiswa (Azhar, 2014). Oleh karena itu bahan ajar diperlukan sebagai panduan mahasiswa dalam kegiatan praktik.

Bahan ajar merupakan media yang berfungsi membantu dosen agar 
mahasiswa terpacu untuk belajar lebih mandiri (Kemenristekdikti, 2016:3). Bentuk-bentuk bahan ajar meliputi cetak serta non cetak. Contoh bahan ajar cetak: materi perkuliahan, pedoman pembelajaran, bahan ajar non cetak: seperti CD pembelajaran, multimedia, dll.

Unsur yang terdapat pada bahan ajar antara lain (1) Petunjuk belajar, (2) Kompetensi, yang akan dicapai, (3) Informasi pendukung, (4) Latihanlatihan, (5) Petunjuk kerja atau lembar kerja, (6) Evaluasi (Prastowo, 2012:28). Berdasarkan kajian dalam pendahuluan hipotesis penelitian ini yaitu. (1) Karakteristik Bahan Ajar Praktikum IPS SD memenuhi kriteria valid dan praktis. (2) Pengaruh Bahan Ajar Praktikum IPS SD terhadap prestasi mahasiswa.

\section{METODE PENELITIAN}

Penelitian ini termasuk penelitian R\&D. Penelitian R\&D bertujuan, menghasilkan produk, kemudian diuji keevektifan prodok yang dihasilkan. (Sugiyono: 2010). Produk baru dalam penelitian ini yaitu bahan ajar Praktikum IPS SD.

\section{Prosedur Pengembangan}

Berdasarkan Samsudi (2009: 90) tahap atau prosedur dalam penelitian ini mengacu pada Tiagarajan yang disebut 4D (Define, Design, Develop, Desiminate). Pada penelitian ini dibatasi hanya 3 tahap sebagai berikut:

1. Define

Dalam tahap ini yang dilakukan yaitu studi lapangan dan studi literatur. Studi lapangan untuk mengetahui masalah yang terjadi dalam perkuliahan praktikum IPS SD SD . Pengumpulan data lapangan yang berkaitan dengan bahan ajar, tanggapan awal mahasiswa terhadap mata kuliah. Studi literatur dilakukan untuk mengetahui solusi yang tepat dari masalah yang didapat melalui studi lapangan.

\section{Design}

Pada studi literatur yang dilakukan maka dirumuskan solusi yang akan dikembangkan yaitu bahan ajar praktikum IPS SD. Setelah dikembangkan sesuai kebutuhan, bahan ajar tersebut diuji validatasnya oleh para ahli, dengan menggunakan lembar validasi 
bahan ajar dengan kriteria yang sudah ditentukan. Setelah itu dievaluasi dan direvisi.

3. Develope

Pada tahap ini bahan ajar praktikum IPS SD diuji cobakan. Bahan ajar praktikum IPS SD diujikan pada mahasiswa PGSD FKIP UNISSULA tahun pelajaran 2018/2019 semester IVA, kelas eksperimen serta semester IVB, kelas kontrol. Desain uji coba ini digunakan untuk menguji bahan ajar yang dikembangkan berbentuk bahan ajar praktikum IPS SD. Desain dalam uji coba produk menggunakan Post Test Only Control Design (Sugiyono, 2010:76). Pada tahap uji coba produk ini juga dikaji pengaruhnya terhadap prestasi belajar mahasiswa.

\section{Instrumen Penelitian}

1. Panduan Wawancara

Panduan wawancara ini dilakukan untuk mengetahui data awal yang berkaitan dengan potensi dan masalah yang terjadi dalam pembelajaran IPS SD pada mahasiswa semester IV PGSD FKIP UNISSULA.

2. Angket

Angket validasi bahan ajar digunakan untuk mengetahui validitas bahan ajar konsep dasar Praktikum IPS SD melalui para validator ahli.

3. Tes Evaluasi Prestasi Belajar

Tes evaluasi prestasi ditujukan guna mengukur pengaruh bahan ajar Praktikum IPS terhadap prestasi belajar.

\section{Teknik Analisis Data}

1. Analisis Data Validitas Bahan Ajar Praktikum IPS SD

Penilaian masing-masing validator atau ahli, terhadap bahan ajar Praktikum IPS SD dimuat dalam bentuk nilai dengan kriteria, dan kesimpulan penilaian. Uraian saran dirangkum dan dideskripsikan secara naratif untuk landasan revisi setiap komponen draf Bahan Ajar Praktikum IPS.

2. Analisis Data Prestasi Belajar

Data tes hasil belajar kognitif dianalisis secara deskriptif kuantitatif. Langkah-langkah dalam 
menganalis hasil tes yang pertama adalah uji normalitas, yakni dengan mengecek data awal berdistribusi normal ataukah tidak. Dipilih metode Liliefors untuk menguji normalitas sampel. Uji normalitas menggunakan metode Liliefors, Menurut Sudjana (2009: 466-465) yaitu:

a. Menentukan hipotesis, yaitu.

b. $\mathrm{H}_{\mathrm{o}}$ : Sampel berasal dari populasi normal.

c. $\mathrm{H}_{1}$ : Sampel tidak berasal dari populasi normal.

d. Taraf signifikansi yang diambil sebesar $5 \%$.

e. Daerah kriteria penolakan.

f. Tolak $H_{o}$ jika $L_{o}$ yang diperoleh dari data pengamatan melebihi $\mathrm{L}$ dari tabel, dalam hal lainnya $\mathrm{H}_{\mathrm{o}}$ tidak ditolak

g. Statistik uji.

- Pengamatan $\mathrm{X}_{1}, \mathrm{X}_{2}, \mathrm{X}_{3}, \ldots$, $X_{n}$ dijadikan bilangan baku $Z_{1}, Z_{2}, Z_{3}, \ldots ., Z_{n}$ dengan rumus $: \mathrm{Z}_{\mathrm{i}}=\frac{X_{1}-\bar{X}}{S}$ Dimana $\bar{X}$ dan S merupakan rata-rata dan simpangan baku.
- Untuk tiap bilangan baku digunakan daftar distribusi normal baku, kemudian dihitung peluang dari : $\mathrm{F}(\mathrm{Zi})$ $=\mathrm{P}(\mathrm{Z} \leq \mathrm{Zi})$

- Selanjutnya menghitung proporsi Z1, Z2, Z3, ...., Zn yang lebih kecil atau sama dengan $\mathrm{Zi}$, proporsi ini dinyatakan dengan $\mathrm{S} \quad(\mathrm{Zi})$ yang diperoleh dengan rumus:

$S(Z i)=\frac{\text { Banyaknya } \mathrm{Z}_{1}, \mathrm{Z}_{2}, \mathrm{Z}_{3}, \ldots \ldots, \mathrm{Z}_{\mathrm{n}}}{\mid F\left(Z_{i}\right) \text { i } S\left(Z_{i}\right) \mid}$

- Menentukan L

- Harga yang paling besar di antara harga-harga mutlak selisih sebut sebagai Lo.

- Kesimpulan Jika L Litung < $\mathrm{L}_{\text {tabel, }}$ maka Ho tidak ditolak. Pada penelitian ini uji normalitas dilakukan pada variabel dependen saja dan diolah menggunakan program SPSS 17. Normalitasnya diketahui dari signifikansi (sig) dalam kolom Kolmogorov- Smornov. Jika nilai sig > 0,05 maka data berdistribusi normal (Sundayana, 2014: 109). 
Uji yang selanjutnya adalah untuk menentukan homogenitas. Tujuan dari uji homogenitas yaitu mengetahui kedua kelompok memiliki varians sama ataukah tidak. Apabila kedua kelompok memiliki varians sama, maka kedua kelompok disebut homogen. Hipotesis yang digunakan yaitu.

$\mathrm{H}_{0}: \sigma_{1}^{2}=\sigma_{2}^{2}$ (Kedua kelas memiliki varians yang sama atau homogen).

$\mathrm{H}_{\mathrm{a}}: \sigma_{1}^{2} \neq \sigma_{2}^{2}$ (Kedua kelas memiliki varian yang tidak sama atau tidak homogen).

Rumus yang digunakan yaitu.

$$
F=\frac{\text { Varians terbesar }}{\text { Varians terkecil }}
$$

Tolak $\mathrm{H}_{0}$ jika $F \geq F_{\frac{1}{2} \alpha\left(V_{1}, V_{2}\right)}$

(Sudjana, 2009: 250).

Analisis data homogenitas penelitian ini dengan uji independent sample T-test menggunakan program SPSS 17. Kolom printout yaitu, kolom sig. Aplabila nilai kolom sig > 0,05 berarti $H_{0}$ diterima (Sukestiyarno, 2010: 118).
Uji yang ketiga adalah uji banding dua sampel . Uji banding dua rata-rata bertujuan menguji hipotesis menggunakan $\mathrm{Uji} \mathrm{T}$. Setelah uji persyaratan meluti uji normalitas, dan homogenitas, selanjutnya dilakukan uji banding dengan kondisi sesuai hasil persyaratan. Rumusan hipotesis.

$$
\begin{aligned}
\mathrm{H}_{\mathrm{O}}: & \mu_{1}=\mu_{2} \text { (rataan kedua } \\
& \text { sampel sama) } \\
\mathrm{H}_{1}: & \mu_{1} \neq \mu_{2} \text { (rataan kedua sampel } \\
& \text { berbeda) }
\end{aligned}
$$

Jika pengujian homogenitas dihasilkan kedua kelompok homogen maka digunakan rumus.

$$
\mathrm{t}=\frac{\mathrm{x}_{1}-\mathrm{x}_{2}}{\mathrm{~s} \sqrt{\frac{1}{\mathrm{n}_{1}}+\frac{1}{\mathrm{n}_{2}}}}
$$

Keterangan:

$$
\begin{array}{ll}
\mathrm{x}_{1} & =\text { rataan sampel pertama } \\
\mathrm{x}_{2} & =\text { rataan sampel kedua } \\
\mathrm{S} & =\text { simpangan baku } \\
& \text { bersama } \\
\mathrm{n}_{1} \text { dan } \mathrm{n}_{2}= & \text { banyaknya masing- } \\
& \text { masing data sampel } \\
& \text { pertama dan kedua }
\end{array}
$$

Jika pengujian homogenitas dihasilkan kedua kelompok tidak homogen maka digunakan rumus. 


$$
\mathrm{t}^{\prime}=\frac{\mathrm{x}_{1}-\mathrm{x}_{2}}{\sqrt{\frac{\mathrm{s}_{1}^{2}}{\mathrm{n}_{1}}+\frac{\mathrm{s}_{2}^{2}}{\mathrm{n}_{2}}}}
$$

Uji normalitas dilakukan dengan SPSS dengan derajat kepercayaan 5\%, jika nilai sig > $5 \%$, maka $\mathrm{H}_{\mathrm{O}}$ ditolak, apabila nilai sig $<5 \%$, maka $\mathrm{H}_{\mathrm{O}}$ diterima (Sukestiyarno, 2010: 114-115).

\section{HASIL DAN PEMBAHASAN}

\section{Produk Bahan Ajar Praktikum IPS SD}

Bahan ajar adalah instructional materials meliputi pengetahuan, keterampilan serta sikap guna mencapai kompetensi pembelajaran. Bahan ajar praktikum IPS SD tergolong bahan ajar cetak yang dikembangkan mengacu pada Prastowo (2012:28) meliputi:

1. Kompetensi Pembelajaran

$$
\text { Sebelum memasuki }
$$

kompetensi pembelajaran dalam

buku panduan praktikum IPS SD halaman paling awal yaitu halaman judul berisi "Nama Media Pembelajaran dalam Praktikum IPS" yang disesuaikan dengan kompetensi pembelajaran.

Berdasarkan Kurikulum saat ini pada tahun pelajaran 2018/ 2019 di SD yaitu Kurikulum 2013, maka dalam buku panduan praktikum IPS SD dicantumkan kompetensi inti, kompetensi dasar, dan jaringan tema yang terdapat mata pelajaran IPS.

2. Informasi Pendukung

Informasi pendukung dalam hal ini meliputi alat dan bahan yang digunakan serta prosedur atau cara pembuatan media.

3. Petunjuk Belajar

Petunjuk belajar berisi langkah-langkah praktik dalam penggunaan media pembelajaran.

4. Petunjuk Kerja atau Lembar Kerja

Dalam setiap akhir pembelajaran terdapat permainan atau kuis untuk mengetahui tingkat pemahaman dari kegiatan yang telah dipraktikkan. Petunjuk kerja berisi cara bermain atau mengerjakan kuis.

$$
\text { Indikator penilaian Buku }
$$

Panduan Praktikum IPS SD dilihat dari aspek: (1) kompetensi yang akan dicapai; (2) informasi pendukung; (3) petunjuk belajar; (4) petunjuk kerja atau lembar kerja. Rekapitulasi hasil validasi 
dan penilaian Buku Panduan

Praktikum IPS SD terdapat pada,

Tabel 1.

Tabel 1. Rekapitulasi Hasil Validasi Film Antikorupsi

\begin{tabular}{clccc}
\hline \multirow{2}{*}{ No } & $\begin{array}{c}\text { Aspek yang } \\
\text { dinilai }\end{array}$ & \multicolumn{2}{c}{ Validator } & $\begin{array}{c}\text { Rata- } \\
\text { Rata }\end{array}$ \\
\cline { 3 - 4 } & I & II & 3,5 \\
\hline 1 & $\begin{array}{l}\text { Kompetensi } \\
\text { yang dicapai }\end{array}$ & 4 & 3 & 3 \\
\hline 2 & $\begin{array}{l}\text { Informasi } \\
\text { pendukung }\end{array}$ & 3 & 3 & 3 \\
\hline 3 & $\begin{array}{l}\text { Petunjuk } \\
\text { belajar }\end{array}$ & 3 & 3 & 3 \\
\hline 4 & Petunjuk kerja & 4 & 3 & $\mathbf{3 , 4}$ \\
\hline Rata-Rata Skor & \multicolumn{3}{c}{ Valid } \\
\hline Kriteria Penilaian & \multicolumn{3}{c}{$\begin{array}{c}\text { Dapat digunakan } \\
\text { dengan revisi }\end{array}$} \\
\hline Keterangan & \multicolumn{3}{c}{}
\end{tabular}

Hasil validasi Buku Panduan

Praktikum IPS SD pada Tabel 1 dengan rata-rata 3,4 dalam kategori baik. Kesimpulan saran validator untuk perbaikan perangkat pembelajaran pada Tabel 1 yaitu.

Tabel 2. Revisi Buku Panduan Praktikum IPS SD

\begin{tabular}{cl}
\hline No & \multicolumn{1}{c}{ Saran Validator } \\
\hline 1 & Sistematika penulisan diperbaiki. \\
\hline 2 & $\begin{array}{l}\text { Kerapian dalam pengemasan buku } \\
\text { panduan agar memiliki nilai jual. }\end{array}$ \\
\hline
\end{tabular}

Uji Coba Lapangan Bahan Ajar Praktikum IPS SD Pengaruhnya terhadap Prestasi Belajar

Kegiatan uji coba lapangan merupakan kegiatan penerapan Bahan Ajar Praktikum IPS SD di kelas untuk mengetahui pengaruhnya terhadap prestasi belajar. Uji coba dalam penelitian ini menggunakan posttestonly kontrol design yaitu terdiri dari satu kelas kontrol, dan satu kelas eksperimen, dari populasi homogen. Subjek uji coba dalam penelitian ini yaitu mahasiswa PGSD semester IVA, yaitu kelas eksperimen dan kelas IVB, kelas kontrol.

1. Hasil Uji Normalitas

Normalitas pada data uji lapanga melalaui uji Kolmogorov Smirnov, menggunakan taraf signifikansi 5\% dengan jumlah data masing-masing 38 . Data mengikuti distribusi normal jika nilai sig hitung lebih besar dari pada 5\%. Berikut hasil perhitungan menggunakan SPSS pada Tabel 3.

Tabel 3. Tests of Normality

\begin{tabular}{lcccccc} 
& \multicolumn{2}{c}{$\begin{array}{c}\text { Kolmogorov- } \\
\text { Smirnov }^{a}\end{array}$} & \multicolumn{4}{c}{ Shapiro-Wilk } \\
\hline & & & \multicolumn{4}{c}{ Statisti } \\
& Statistic & Df & Sig. & $\boldsymbol{c}$ & Df & Sig. \\
\hline $\begin{array}{l}\text { Kelas } \\
\text { eks }\end{array}$ & 0,12 & 38 & 0,17 & 0,96 & 38 & 0,16 \\
& & & & & & \\
\hline $\begin{array}{l}\text { Kelas } \\
\text { kontrol }\end{array}$ & 0,14 & 38 & 0,08 & 0,96 & 38 & 0,21 \\
\hline
\end{tabular}

Kelas eksperimen menghasilkan nilai sig $=0,17$ dan kelas kontrol menghasilkan nilai sig $=0,08$. Karena 
nilai sig kelas eksperimen dan kelas kontrol lebih besar 5\% sehingga kedua data berdistribusi normal.

2. Hasil Uji Homegenitas

Uji homogenitas data kelas eksperimen serta kelas kontrol, menggunakan uji Levene, dengan taraf signifikan sebesar 5\% dengan jumlah data masing-masing 38. Kedua data homogeny, apabila nilai sig hitung lebih besar dari 5\%. Berikut hasil perhitungan menggunakan SPSS pada Tabel 4.

Tabel 4. Levene's Test for Equality of Variances

\begin{tabular}{llcc}
\hline & & $\begin{array}{c}\text { Levene's Test for } \\
\text { Equality of } \\
\text { Variances }\end{array}$ \\
\hline Prestasi & F & Sig. \\
\hline & $\begin{array}{l}\text { Equal variances } \\
\text { assumed }\end{array}$ & 1,60 & 0,21 \\
\cline { 2 - 4 } & $\begin{array}{l}\text { Equal variances } \\
\text { not assumed }\end{array}$ & \\
\hline
\end{tabular}

Pada tabel Levene's Test for Equality of Variances menunjukkan nilai sig $=0,21=21 \%>5 \%$ sehingga dapat disimpulkan bahwa kedua data pretest memiliki variansi yang sama atau homogen.

3. Hasil Analisis Uji Banding

Uji banding dalam hal ini bertujuan membandingkan rata-rata evaluasi prestasi belajar kelas eksperimen, dengan kelas kontrol. Dipilih deretan baris Equal Variances Assumed, karena kedua kelas homogen. Hipotesis yang akan diuji adalah.

$\mathrm{H}_{0}: \mu_{1}=\mu_{2}$ ( tidak ada perbedaan nilai rata-rata hasil belajar antara kelas eksperimen dengan kelas kontrol)

$\mathrm{H}_{1}: \quad \mu_{1} \neq \mu_{2}$ ( ada perbedaan nilai ratarata hasil belajar antara kelas eksperimen dengan kelas kontrol)

Hasil perhitungan menggunakan SPSS menunjukkan nilai pada kolom sig (2tailed) kolom t-test for Equality of Means sebesar $\quad 0,002<0,05$ menunjukkan $\mathrm{H}_{0}$ ditolak, berarti hasil belajar kelas eksperimen dengan kelas kontrol berbeda signifikan. Untuk menentukan kelas mana yang mempunyai rata-rata jauh lebih tinggi digunakan analisis Group Statistics yang dapat dilihat pada Tabel 5.

Tabel 5. Group Statistics

\begin{tabular}{|c|c|c|c|c|c|}
\hline & Kelas & $\mathbf{N}$ & Mean & $\begin{array}{c}\text { Std. } \\
\text { Deviation } \\
\end{array}$ & $\begin{array}{c}\text { Std. } \\
\text { Error } \\
\text { Mean }\end{array}$ \\
\hline \multirow{2}{*}{$\begin{array}{l}\text { Pres- } \\
\text { Tasi }\end{array}$} & Eksperimen & 38 & 84,74 & 9,15 & 1,48 \\
\hline & Kontrol & 38 & 78,50 & 7,70 & 1,25 \\
\hline
\end{tabular}


$\begin{aligned} & \text { Rata-rata hasil belajar siswa } \\ & \text { pada kolom mean, tabel Group }\end{aligned}$

Statistics diperoleh 84,74 untuk kelas eksperimen dan 78,50 untuk kelas kontrol. Hasil tersebut menunjukkan bahwa hasil belajar kelas eksperiman lebih baik dibandingkan dengan kelas kontrol.

\section{SIMPULAN}

1. Menghasilkan produk berupa buku panduan praktikum IPS SD yang berisi: kompetensi pembelajaran, informasi pendukung, petunjuk belajar, lembar kerja.

2. Prestasi belajar mahasiswa dari analisis uji $\mathrm{T}$, kelas eksperimen menunjukkan rata-rata 84,74 lebih tinggi, dibandingkan kelas kontrol memiliki rata-rata 78,50 .

\section{DAFTAR PUSTAKA}

Hidayati. 2008. Pengembangan Pendidikan IPS SD. Jakarta: Depdiknas.
Supardan, D. 2015.Pembelajaran Ilmu Pengetahuan Sosial Perspektif Filosofi dan Kurikulum. Bandung: Bumi Aksara.

Kemenristekdikti. 2016. Panduan Program Insentif Bahan Ajar dan Pedoman Pembelajaran. Kemenristekdikti:Jakarta.

Prastowo, A. 2012. Panduan Kreatif Membuat Bahan Ajar Inovatif. Jogjakarta. DIVA Press.

Samsudi. 2009. Desain Penelitian Pendidikan.Semarang: Unnes Press.

Sugiyono. 2010. Metode Penelitian Pendidikan Kuantitatif, Kualitatif, dan R\& D. Bandung: Alfabeta.

Sudjana, N. 2009. Dasar-Dasar Proses Belajar Mengajar. Bandung: Sinar Baru Algensindo.

Sukestiyarno. 2010. Olah Data Penelitian Berbantuan SPSS. Semarang: UNNES.

Sundayana. 2014. Statistika Penelitian Pendidikan. Bandung: Alfabeta. 